\section{S sciendo DIMENSIONING OF DANGER ZONES EMERGING AS A DOMINO EFFECT OF AN LNG EXPLOSION FOR INDUSTRIAL PLANTS LOCATED IN THE VICINITY OF INLAND TRANSPORT FAIRWAYS}

DOI 10.2478/ntpe-2018-0009

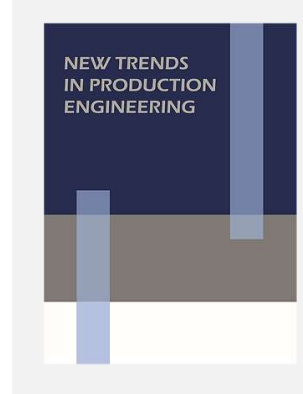

2018

Volume 1

Issue 1

pp. 73-79

\author{
Agnieszka Kalbarczyk-Jedynak, PhD. Eng. \\ Prof. Wojciech Ślączka, PhD. Eng. \\ Maritime University of Szczecin, Poland
}

\begin{abstract}
The development of new technologies, the use and transport of LNG increases the number of investments that may mutually affect their safety on account of a domino effect. It means that a breakdown caused by one of the business entities may contribute to the escalation of a problem through thermal energy emission in another entity. The energy absorbed in an adjacent technological process line may cause irreparable damage despite the security measures employed. When planning an investment of a pioneering nature, one ought to consider not only the modern technologies used in a newly designed installation, but one must also pay attention to the direct neighbourhood of other industrial plants and the planned infrastructure, e.g. for gas transport or transhipment. Such a synergistic approach guarantees the safety of undertaken activities and ensures a stable, breakdown-free operation of all the business entities located in a given area. This paper discusses the issue of mutual influence exerted by two independent entities located within a small distance of one another, i.e. salt processing plant and a vessel transporting an LNG mixture. The authors considered a situation in which a breakdown occurs in an industrial plant and in which the released energy causes damage to a tank shell of an LNG carrying vessel on an inland fairway. In the examined situation the types of risks arising from LNG tank shell damage on-board an inland vessel were defined and the dimensions of the resulting danger zones were determined in a function of concentration of individual LNG components as well as the pressure and temperature generated inside the tank. The shape of the tank was also taken into consideration, since it affects fractioning in the course of the release of the substance accumulated in it. The analysis was conducted on the basis of DNV Phast 7.11 software.
\end{abstract}

Keywords: BLEVE, LNG, Phast, danger zones, domino effect

\title{
INTRODUCTION
}

The implementation of new industrial projects frequently requires an additional analysis regarding in particular operation risks. The risk analysis ought to be conducted at the level of designing an industrial plant itself, as well as at the level of operation, and in particular the mutual impact exerted on the surrounding environment as well as on industrial infrastructure. Mutual influence of two or a greater number of business entities, using LNG in their operation and manufacturing processes, results in an increased risk of a breakdown and consequently of an explosion on account of a domino effect. In such circumstances it is worth considering an additional technological security measure and an analysis of danger zone dimensions. In order to minimise the risk of failure, security devices are used. When a location for a new industrial plant is planned, not only that investment's own needs ought to be considered, but also its interactions with adjacent investment projects as well as with already existing manufacturing plants (Oueidat et al., 2015). This wider outlook is important on account of people's safety and safe operation of an enterprise. The creation and development of a responsible enterprise concept is a resultant of the sense of security experienced by the enterprise employees as well as the neighbouring companies' employees and the persons residing in the direct vicinity of a potential investment. When considering the location for an industrial plant, it is crucial to take into account the dimensions of any possible danger zones and to analyse the most dangerous scenarios, despite a low probability of them occurring. An attempt of finding a suitable location for salt processing plant could serve as an example. The location in a direct vicinity of a river is 
an important factor for such an investment. It allows, inter alia, for the use of an additional way of transport, namely an inland waterway. Inland navigation is an alternative for the diversification of LNG distribution, especially since with time that type of transport will become increasingly more economic. It means that a wide range of products will be more frequently carried by such mode of transport - including hazardous materials and LNG. Therefore, a question arises as to what impact a breakdown in a manufacturing facility located close to an inland waterway may have on passing barges or other vessels. Taking into consideration continuous demand for energy, a situation simulation may be attempted in which a vessel carries LNG. Contrary to what one might expect, it is a fairly realistic concept, since in order to increase its transhipment potential, the LNG port will be forced to seek alternative ways of LNG transport. Furthermore, LNG will be increasingly more often used as fuel in inland transport, as this type of fuel enables reducing the emission of solid particles and sulphur compounds and significantly decreasing the emissions of nitrogen oxides and $\mathrm{CO}_{2}$. In the event of a breakdown, even if high temperatures are not used in a manufacturing facility, thermal energy emission may occur on account of the contact of the substance from uncontrolled depressurisation with another seemingly safe preparation. In that way a manufacturing facility, using the technologies in which the range of employed temperatures does not exceed $100^{\circ} \mathrm{C}$, may be a source of a significant dose of energy coming from a chemical reaction - an explosion that occurred on 2 May 2018 at one of Meridian Magnesium plants may serve as an example of the above. The explosion involved losses exceeding half the value of the plant (Hazex, 2018). Coming back to the concept of a salt processing plant, the claim that in a given enterprise it is impossible to generate a significant portion of energy that is emitted into the environment, because the evaporators used operate under reduced pressure enabling a decrease of temperature of equipment operation, loses its significance in such context. The contact of two or a greater number of substances may lead to an exogenous reaction of dangerous consequences. Furthermore, an explosion caused by such a reaction may impact on the environment and cause a secondary explosion, if another dangerous substance is found in it (Zhengh et al., 2018). Such a situation is a perfect example of a BLEVE phenomenon (Zhang and Liang, 2013). According to its definition, an explosion described as BLEVE (Boiling Liquid Expanding Vapour Explosion) is a dynamic physical process related to a tank blowout and a rapid phase transformation of the liquid accumulated in it (Lesiak and Porowski, 2012). Such a transformation takes place when the temperature of the liquid accumulated in a tank exceeds the boiling temperature of the analysed liquid at regular atmospheric pressure (Li and Huang, 2012). An incident of the kind may easily occur when we consider an LNG tank. If we examine a case in which an external shell of a tank containing LNG is damaged and if we add to it the thermal energy from a possible breakdown in a neighbouring industrial plant, then we arrive at a scenario of a highly dangerous situation related to a rapid release and propagation of a flammable substance (Vandebroek and Berghmans 2012).

\section{INITIAL CONDITIONS}

In order to represent real conditions, two liquefied gas types were analysed: light LNG and heavy LNG (Sedlaczek, 2008). Both of these LNG types are delivered to the transhipment and regasification terminal in Świnoujście (Poland). The chemical composition of both of these LNG types is represented in Table 1.

Table 1.

Volumetric percentage of the hydrocarbons comprised in LNG mixtures

\begin{tabular}{|c|c|c|}
\hline \multirow[t]{2}{*}{ Components } & \multicolumn{2}{|c|}{ LNG } \\
\hline & Light $[\% \mathbf{V}]$ & Heavy $[\% \mathbf{V}]$ \\
\hline Methane & 95.40 & 87.00 \\
\hline Ethane & 3.20 & 8.37 \\
\hline Propane & 0.00 & 3.00 \\
\hline Butane + isobutane & 0.00 & 1.20 \\
\hline Pentane & 0.00 & 0.23 \\
\hline Nitrogen & 1.40 & 0.20 \\
\hline
\end{tabular}

Source: (PolskieLNG.pl, 2018) 
In the conducted simulation two locations of LNG transporting barges were considered. In both cases we deal with areas in which, apart from access to a waterway, salt deposits are located and for the purpose of the simulation - a salt processing plant as well. It is significant, because in the future energy raw materials, including liquid and volatile hydrocarbons, can be stored in those areas - it concerns both the workings themselves as well as salt domes. The effect of operating a salt processing plant involves the creation of natural earth caverns. In that context an analysis and dimensioning of the emergence of danger zones were conducted for Lubczyna village near Goleniów, located in Szczecin Depression. It features salt domes piercing through Mesozoic geological layers. The area is highly attractive in terms of a possible construction of a cavern gas warehousing, since a salt mirror lies at the depth of approx. $890 \mathrm{~m}$ (Czapowski and Bukowski, 2009). The probability of building a potential gas cavern at the site increases along with the amount of gas deliveries for Orlen concern transported via LNG port in Świnoujście and along with inland navigation development on the Oder Waterway. The creation of such a gas cavern will enable raising energy security of a given region in the future. The second location considered is Siekierki village in Gryfino district, in Cedynia municipality. The choice of the location is dictated by the greatest transit depth for the Oder River - at this section its depth is $3.71 \mathrm{~m}$ at water level equal to $5.23 \mathrm{~m}$. In that area we deal with salt domes not piercing through Mesozoic geological layers (Czapowski and Bukowski, 2009). In both cases the reconnaissance of the salt domes geological built has been extremely limited so far. The analysed LNG volume currently carried by inland navigation vessels amounts to $2250 \mathrm{~m}^{3}$ approximately, provided that a tank is $95 \%$ full. It was assumed that as a result of shell damage and depending on the technology of its manufacture, the tank can sustain the pressure within the range of 1.2 bar to 3.2 bar] Simulations were conducted for Pasquill stability D and F classes. Maximum wind speed value for the conducted calculations was set at $15 \mathrm{~m} / \mathrm{s}$. For $\mathrm{F}$ class stability the wind speed range was between $1.5 \mathrm{~m} / \mathrm{s}$ and $3 \mathrm{~m} / \mathrm{s}$. Furthermore, the impact of a tank shape on the dimensions of danger zones was examined. Spherically and cylindrically shaped tanks were considered in the simulation process.

\section{RESULTS AND DISCUSSION}

Potential dimensions of danger zones were determined for the parameters set above and the energy released as a result of a BLEVE-type depressurisation was determined for variable temperature and pressure values created inside an LNG tank on-board an inland vessel. The data obtained in the simulation are presented in the tables below (Table 2 and Table 3 ).

Table 2.

Ranges of danger zones and calculated explosion energy for light LNG

\begin{tabular}{|c|c|c|c|c|}
\hline \multirow{2}{*}{$\begin{array}{l}\text { Presure } \\
\text { bar] }\end{array}$} & \multirow{2}{*}{$\begin{array}{c}\text { Temperature } \\
{ }^{\circ} \mathrm{C}\end{array}$} & \multicolumn{2}{|c|}{ Radius in $\mathrm{m}$ for } & \multirow{2}{*}{$\begin{array}{c}\text { Energy } \\
\text { kJ }\end{array}$} \\
\hline & & Spherical tank & Cylindrical tank & \\
\hline \multirow[t]{4}{*}{1.2} & -80 & 1368 & 1839 & $3.0 \cdot 10^{8}$ \\
\hline & -100 & 1311 & 1763 & $2.7 \cdot 10^{8}$ \\
\hline & -120 & 852 & 1146 & $7.7 \cdot 10^{7}$ \\
\hline & -140 & 824 & 1108 & $6.7 \cdot 10^{7}$ \\
\hline \multirow[t]{4}{*}{2.2} & -80 & 1037 & 1339 & $3.8 \cdot 10^{8}$ \\
\hline & -100 & 997 & 1339 & $1.2 \cdot 10^{8}$ \\
\hline & -120 & 953 & 1281 & $1.1 \cdot 10^{8}$ \\
\hline & -140 & 958 & 1288 & $1.0 \cdot 10^{8}$ \\
\hline \multirow[t]{4}{*}{3.2} & -80 & 1098 & 1476 & $1.6 \cdot 10^{8}$ \\
\hline & -100 & 1055 & 1418 & $1.5 \cdot 10^{8}$ \\
\hline & -120 & 1024 & 1376 & $1.3 \cdot 10^{8}$ \\
\hline & -140 & 436 & 586 & $1.3 \cdot 10^{8}$ \\
\hline
\end{tabular}

A comparison of danger zones dimensions for both LNG mixtures analysed demonstrates that a greater radius of explosion danger zone is always obtained for light LNG than in the case of the heavy LNG type for any temperature values between the range of $-80^{\circ} \mathrm{C}$ to $-140^{\circ} \mathrm{C}$ and for any pressure value within the range of 1.2 bar -3.2 bar. This relationship has been presented in Fig. 1 for the temperature of $-80^{\circ} \mathrm{C}$ and an initial pressure equal to $2.2 \mathrm{bar}$ in the case of light LNG and heavy LNG (Fig. 1). The areas marked with circles in grey, brown and purple describe 
the overpressure of 0.21 barg, 0.14 barg and 0.02 barg, respectively for light LNG, while red, green and blue colours were assigned to heavy LNG to the overpressure of $0.21 \mathrm{barg}, 0.14$ barg and 0.02 barg, respectively. The lowest overpressure value practically corresponds to the atmospheric pressure.

Table 3.

Ranges of danger zones and calculated explosion energy for heavy LNG

\begin{tabular}{|c|c|c|c|c|}
\hline \multirow{2}{*}{$\begin{array}{l}\text { Pressure } \\
\text { bar }\end{array}$} & \multirow{2}{*}{$\begin{array}{c}\text { Temperature } \\
{ }^{\circ} \mathrm{C}\end{array}$} & \multicolumn{2}{|c|}{ Radius in $\mathrm{m}$ for } & \multirow{2}{*}{$\begin{array}{c}\text { Energy } \\
\text { kJ }\end{array}$} \\
\hline & & Spherical tank & Cylindrical tank & \\
\hline \multirow[t]{4}{*}{1.2} & -80 & 1392 & 1871 & $2.9 \cdot 10^{8}$ \\
\hline & -100 & 1338 & 1798 & $2.5 \cdot 10^{8}$ \\
\hline & -120 & 881 & 1185 & $7.0 \cdot 10^{7}$ \\
\hline & -140 & 840 & 1129 & $6.3 \cdot 10^{7}$ \\
\hline \multirow[t]{4}{*}{2.2} & -80 & 1501 & 2017 & $1.3 \cdot 10^{8}$ \\
\hline & -100 & 1030 & 1385 & $1.1 \cdot 10^{8}$ \\
\hline & -120 & 986 & 1325 & $9.7 \cdot 10^{7}$ \\
\hline & -140 & 970 & 1304 & $9.9 \cdot 10^{7}$ \\
\hline \multirow[t]{4}{*}{3.2} & -80 & 1134 & 1525 & $1.5 \cdot 10^{8}$ \\
\hline & -100 & 1091 & 1466 & $1.3 \cdot 10^{8}$ \\
\hline & -120 & 1050 & 1412 & $1.2 \cdot 10^{8}$ \\
\hline & -140 & 1046 & 1405 & $9.3 \cdot 10^{6}$ \\
\hline
\end{tabular}

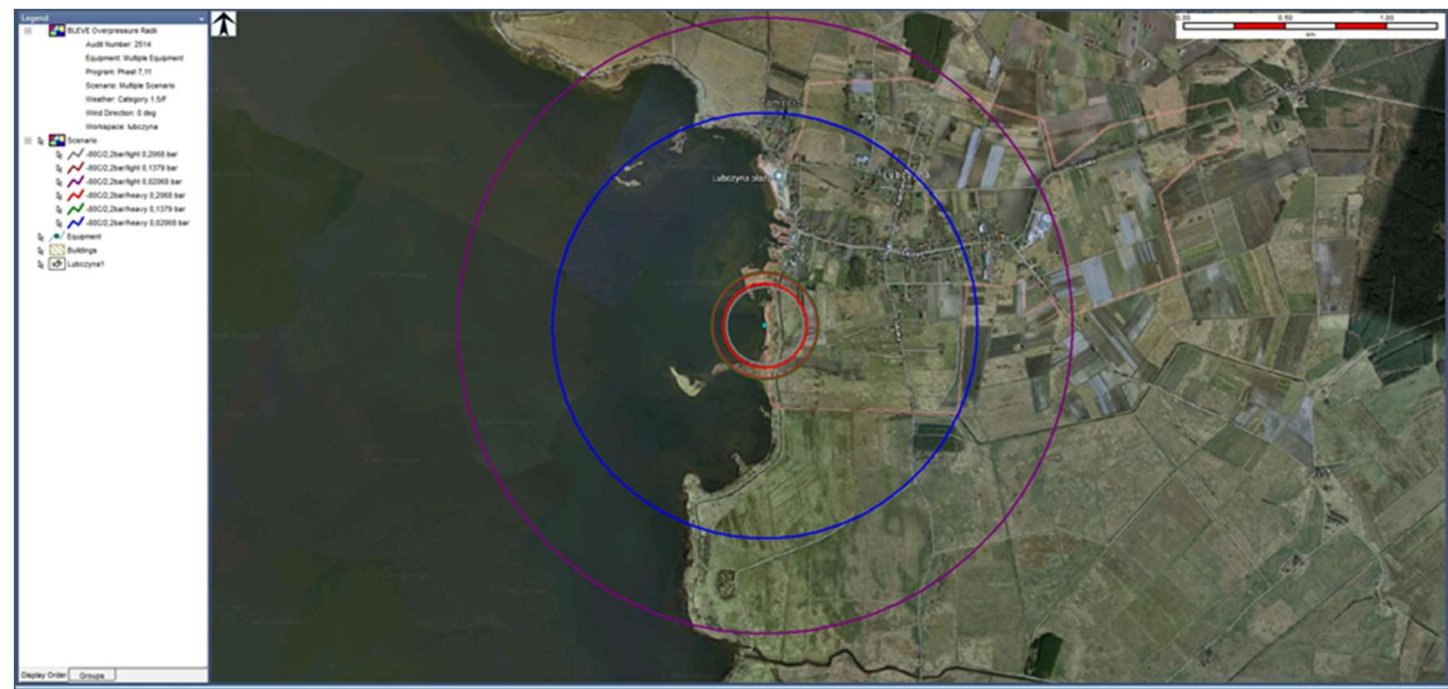

Fig. 1. Dimensioned danger zones for the temperature equal to $-80^{\circ} \mathrm{C}$ and pressure of $2.2 \mathrm{bar}$ for light LNG and heavy LNG for Lubczyna village

In the event of substance release in the analysed situations for a BLEVE-type scenario, surface roughness, coast type or Pasquill stability as well as wind speed do not affect the radii of the danger zones created as a result of a depressurised tank containing LNG. All the values of the obtained sizes of danger zones are extremely similar to one another, nearly identical. This is due to the energy generated upon substance release - it is much higher than the energy coming from wind speed, turbulence resulting from Pasquill stability, or surface roughness. The size of explosion risk areas depends both on LNG temperature (Fig. 2), as well as on the increase of inside tank pressure (Fig. 3). Gas pressure influences the temperature of the substance accumulated in a closed tank; similarly, temperature determines pressure in accordance with Benedicta-Webb-Rubin equation. Although for a set pressure value inside an LNG tank, the radius of an explosion danger zone increases along with temperature rise, but for higher pressure of 3.2 bar a change of that pressure does not result in any visible differences in the range of a danger zone. It is determined by a variable share of the gaseous phase relative to the liquid phase of LNG in the event of pressure and temperature change. 


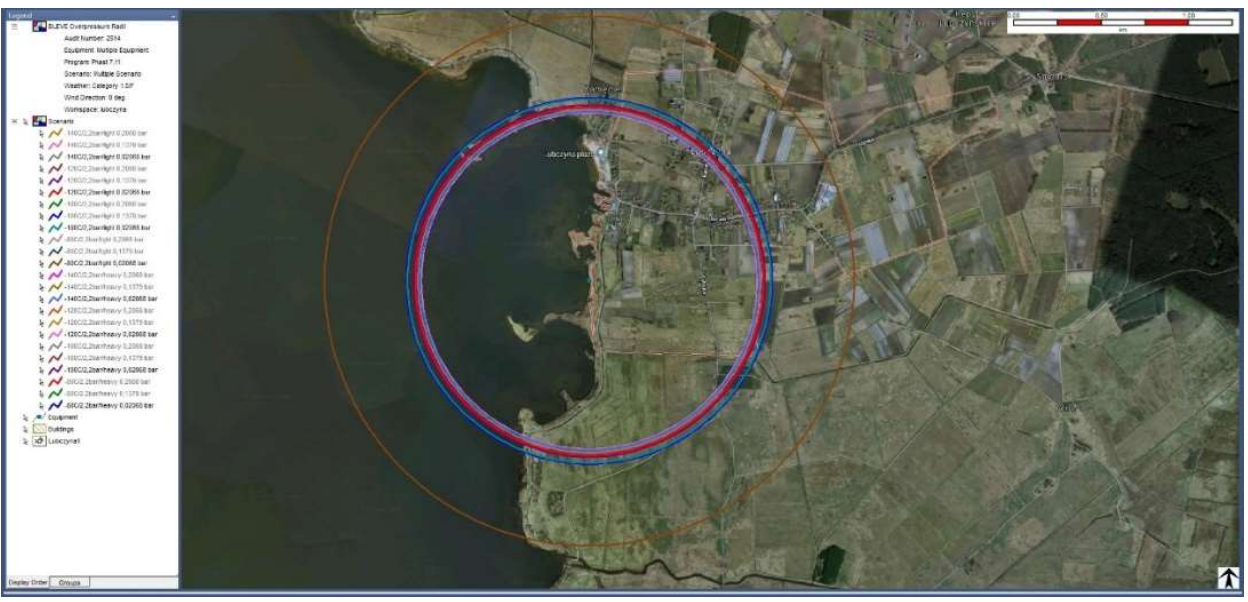

Fig. 2. Dimensioned danger zones for temperatures equal to $-80^{\circ} \mathrm{C},-100^{\circ} \mathrm{C},-120^{\circ} \mathrm{C}$ and $-140^{\circ} \mathrm{C}$ and pressure of 2.2 bar for light LNG and heavy LNG for Lubczyna village

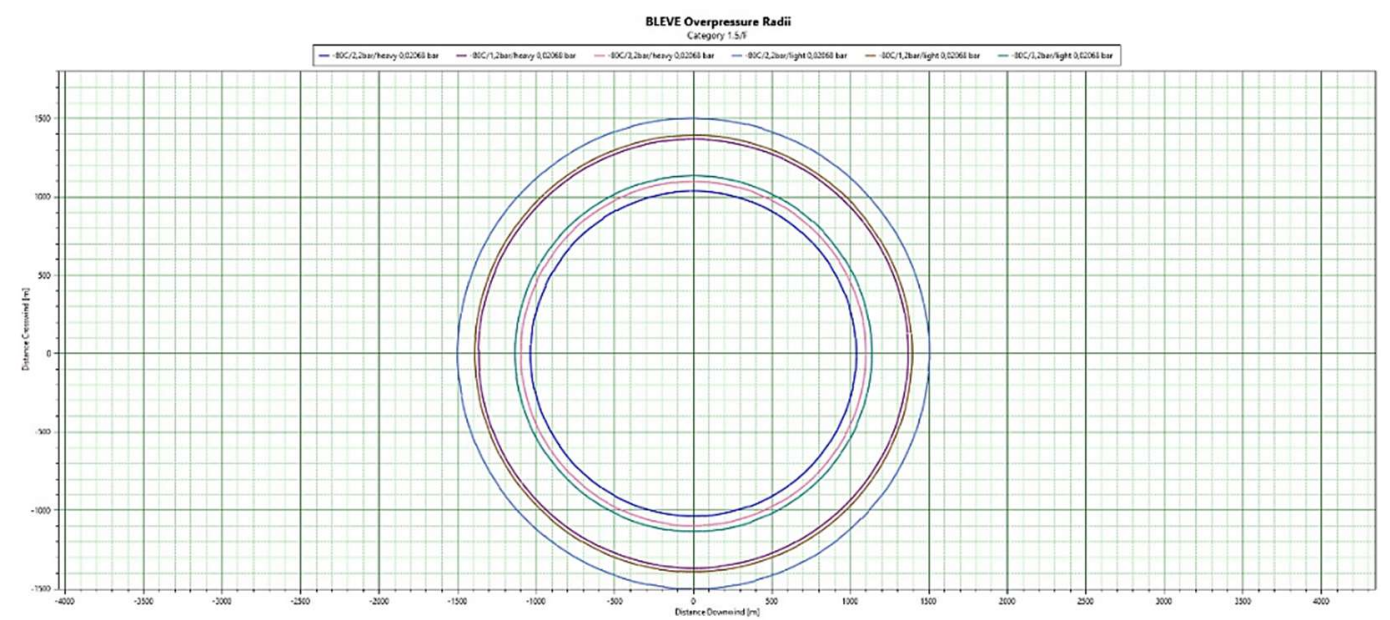

Fig. 3. Dimensioned danger zones for temperatures equal to $-80^{\circ} \mathrm{C}$ and for pressures ranging between 2.1 bar and - 3.2 bar for heavy LNG and light LNG for Lubczyna village

A seeming anomaly of a danger zone range for a set temperature value and a variable pressure value can be explained in the same way. Analysing the data from Table 2 and Table 3, it becomes noticeable that along with pressure increase at a set temperature value, the radii of danger zones shrink, which is caused by a decrease of the share of gaseous phase in the mixture. However, those values are not directly proportional to one another, since in the case of heavy LNG deviations from the rule can be observed. It means that the dimensions of the analysed zones are also affected by the percentage share of individual components, which differ in vapour pressure. The aforementioned pressure influences a disturbance of the range function depending on temperature and pressure, since it effectively disrupts the mutual relation between pressure and temperature. Furthermore, the share percentage of individual LNG components affects the upper and lower explosion limit. Each of those components features different explosion limits. This in turn impacts on explosion energy, which directly translates into the size of a danger zone. The shape of a tank affects the range of a danger zone determined by both fractioning of the tank as well as the speed of the released substance (Dongliang et al., 2014). In the case of cylindrical tanks the dimensions of the discussed zones are a little over $30 \%$ larger relative to the data obtained for a spherical shape.

\section{CONCLUSION}

In the analysed cases the influence of an industrial plant on inland transport has a significant impact on human health and safety. The location of a salt processing plant does not exert a greater impact on the range of released LNG mixture, since the surface shape and atmospheric conditions will not considerably affect the size of a BLEVE-type explosion danger zone. The 
released energy accompanied by such a type of depressurisation is so great that the surface roughness, or Pasquill stability and coastline type are no longer of significance. However, it needs to be stressed that the distance between energy emission source, in the form of heat, in this case a salt processing plant, and a reservoir of a hazardous substance is extremely important, since the energy reaching an LNG tank will depend precisely on the size of a zone dividing both entities and on the types of damage occurring in the salt processing plant. In such circumstances failure-free operation of an industrial facility is a major factor, since the energy released during a possible explosion may cause damage to the shell of a tank containing hazardous substances. A breach of a tank shell on-board an inland vessel causes LNG temperature to rise, which entails an immediate change of pressure inside the tank. Transition from a liquid to gaseous phase is equivalent to an approximate 600 -fold increase of LNG volume. It may be the cause of a tank wall rupture, which will consequently cause a rapid leakage of the tank contents and its blowout. This is a BLEVE phenomenon, in which thermal radiation, an overpressure wave and fractioning occur, which is clearly affected by a tank shape. In the case of cylindrical tanks the speed of released substance is not constant on account of the nonuniform structure - hence the danger zones radii increase. In the event of a BLEVE-type phenomenon, it is evident that the phenomenon is accompanied by thermal radiation, which is defined through heat flux density. The threshold density of heat radiation flux causing physical pain in people oscillates at around $2.5 \mathrm{~kW} / \mathrm{m}^{2}$. Heat flux density for a BLEVE-type phenomenon assumes the value of $250 \mathrm{~kW} / \mathrm{m}^{2}$ (Guzewski et al., 2016). Such a danger level causes the discomfort in people in the direct neighbourhood of the discussed business entities and it ought to be the driving force for further actions aiming at implementing procedures in the event of failure. The factors to which attention needs to be paid when creating the aforementioned procedures, determining danger zones dimensions, include: thermal radiation coming from an explosion in a neighbouring industrial facility, overpressure and temperature generated inside an LNG tank located on a waterway, the shape of a tank itself as well as the composition of an LNG mixture. Such an approach permits minimising catastrophic effects of LNG release into the environment.

\section{REFERENCES}

Czapowski, G. and Bukowski, K., (2009). Salt deposits in Poland - the current state and perspectives for management of the resources. Przegląd Geologiczny, 57(9).

Dongliang, S., Juncheng, J., Mingguang, Z. and Zhirong, W. (2014). Influence of the Cylindrical Source Size on Impact Probability Caused by Fragments. Procedia Engineering, 84, pp. 786-795.

Zheng, F., Zhang, M., Song, J. and Chen, F. (2018). Analysis on Risk of Multi - factor Disaster and Disaster Control in Oil and Gas Storage Tank. Procedia Engineering, 211, pp. 10581064.

Guzewski, P., Wróblewski, D. and Małozięć, D. (2016). Czerwona Księga Pożarów: Wybrane problemy pożarów oraz ich skutków. Józefów: CNBOP-PIB.

Hazex.eu, (2018). Available at: http://www.hazex.eu/30-mln-zl-strat-po-wybuchu-pylumagnezu/ [Accessed 21 May 2018].

Li, J. and Huang, Z. (2012). Fire and Explosion Risk Analysis and Evaluation for LNG Ships. Procedia Engineering, 45, pp. 70-76.

Oueidat, D., Guarnieri, F., Garbolino, E. and Rigaud, E. (2015). Evaluating the Safety Operations Procedures of an LPG Storage and Distribution Plant with STAMP. Procedia Engineering, 128, pp. 83-92.

PolskieLNG.pl, (2018). PolskieLNG Official Webside. [online] Available at: hhttp://www.polskieLNG.pl/strefa-klienta/terminal-Ing/paramety-lng [Accessed 20 Apr. 2018].

Sedlaczek, R. (2008). Boil-Off in Large and Small Scale LNG Chains. Diploma thesis, Norwegian University of Science and Technology, Trondheim.

Vandebroek, L. and Berghmans, J. (2012). Safety Aspects of the use of LNG for Marine Propulsion. Procedia Engineering, 45, pp. 21-26.

Zhang, Q. and Liang, D. (2015). Thermal Radiation and Impact Assessment of the LNG BLEVE Fireball. Procedia Engineering, 52, pp. 602-606. 
Lesiak, P. and Porowski, R. (2012). Ocena skutków awarii przemysłowej w instalacjach procesowych, w tym efektu domino - część 1. Bezpieczeństwo i Technika Pożarnicza, 3, pp. 13-26.

Date of submission of the article to the Editor: 06/2018

Date of acceptance of the article by the Editor: 09/2018 